\title{
Compatibility and Conflict: Negotiation of Relationships by Dizygotic Same-Sex Twin Girls
}

\author{
Susan Danby and Karen Thorpe \\ Centre for Learning Innovation, Faculty of Education, Queensland University of Technology, Brisbane, Australia
}

\begin{abstract}
T his article conceptualizes the child as having active agency in the constructions of their social worlds, and reports on a study that understands the twin experiences from the perspectives of the twins. It examines how twins account for their relationships with their co-twins. The study drew on accounts of 60 twin children - 10 monozygotic (MZ), 10 dizygotic (DZ) same-sex, $10 \mathrm{DZ}$ opposite-sex pairs - aged 5 to 10 years and their parent $(n=30)$. The children engaged in a sticker activity in which they represented their friendships, including their friendship with their co-twin. Using the task as a resource, the children were asked about their friends, the attributes of friendship and examples of everyday friendships encounters. These were audio-recorded and transcribed. Further, parents completed a questionnaire that provided demographic information and asked parents about the children's social experiences including twin children's time spent together, shared interests and their co-twin relationship. Using data from the pictorial representation from the sticker task and parent questionnaires, differences in relationship between MZ, DZ same-sex and DZ opposite-sex twins were examined and used to select a smaller sample for detailed study. DZ same-sex twins tended to view their co-twin less favorably and there was a nonsignificant trend in which conflict was elevated, compared to the other two groups. Based on these findings, the transcripts selected for analysis focuses on the DZ same-sex girls. The girls reported that they had differences of thought, activity and self-presentation. Conflict, competition and challenge as types of social interaction were described, suggesting that the everyday relationship of the twin with her co-twin is always being negotiated and realigned. Evident here is the complexity of social interactions in which the twins engaged everyday with each other.
\end{abstract}

This article investigates the social interactions and qualities of twinship constructed among twins. It examines how twins account for their relationship with their co-twins and their friendships. This article analyses the conversations between a researcher and a number of individual twin participants as they consider the experiences of being a twin, and what twinship might entail for each.

\section{From the Standpoint of Children}

Recent research with children is addressing ways of listening to children on issues that affect them. This approach requires an understanding that children are capable of consulting with adults. This approach is gaining increasing attention, and underpins theory, policy and social practice agendas internationally (Edwards \& Alldred, 1999; Mason \& Fattore, 2005; Prout \& Hallett, 2003; Tayler et al., 2004; see Hallett \& Prout, 2003, for further examples). The increasing preference for consulting children about issues that affect them underlies theoretical understandings that children are active in constructing their social environments. That is, children are reliable informants of their own experiences, and capable of sophisticated engagement.

This article advances beyond adult measurement and interpretation of children's social interaction to include observations of, and accounts from, children themselves. The examination of the lives of children from their own perspectives has been predominantly undertaken with singleton children, where children have been asked about everyday experiences in home and school contexts (Christensen \& James, 2000; Danby \& Farrell, 2004, 2005; Mayall, 2002). For example, Danby and Farrell (2005) asked young children about their experiences and understandings of engaging in the research consent process. Despite many describing the experience of providing consent as a new experience in their lives, the children, through their interview talk, demonstrated their competence as research participants and as informants of their own experiences. This notion of understanding the experiences of children from the child standpoint is one that challenges well-established research perspectives that view the child as a silent and passive recipient of adult social order. Rather, it conceptualizes the child as

Received 27 October, 2005; accepted 17 November, 2005.

Address for correspondence: Susan Danby, Centre for Learning Innovation, Faculty of Education, QUT, Victoria Park Road, Kelvin Grove, Brisbane 4059, Australia. E-mail: s.danby@qut.edu.au 
having active agency in the constructions of their social worlds. This article reports on a study that applies the 'child standpoint' method (Mayall, 2002) to twin populations (Danby \& Thorpe, 2004).

\section{Children Are Competent in Actively Constructing Their Social Worlds}

Everyday understandings about twins can also reflect adult normative assumptions that are not supported within the twin research literature. For example, one common sense assumption about the relationship between children who are twins is that twins share a single social personality, and so can be treated as one single entity (for further discussion, see Stewart, 2003). However, this everyday assumption is challenged by research within behavioral genetics where normative assumptions maintain that what makes up the child's world includes genetics and environment (shared and unshared with sibling). Behavioral genetics studies have been powerful in indicating that children are not only influenced by their genetics and environmental experiences, but also that they express their genetic predispositions and actively construct their environment (see Plomin, 1993; Scarr, 1992). Similarly, the sociology of childhood understands children as actively constructing their social worlds through their interactions with others, including siblings, parents, friends, and teachers (Danby, 2005; Danby \& Thorpe, 2004; James et al., 1998; Mayall, 2002; Waksler, 1991). Within both these research perspectives, children are described as competent and active participants in everyday social environments.

\section{Constructing Twin Relationships: Negotiations, Competition and Conflict}

The article reports on a subset of data from a study that investigated the social worlds of friendship constructed among twins and their friends. More specifically, the article focuses on how the children describe their relationships with their co-twins, and how they negotiate these relationships. Evident in these accounts by the twins is how conflict, as a type of social interaction, is negotiated within the twin pairs.

A key feature of peer culture is 'young children ... doing things together' (Corsaro \& Molinari, 1990, p. 221). This description can apply even to conflict situations, when children deal with each other in particular ways that may involve disputes, exclusion, friendship bids, protection of play space and personal items, aggression and accusations. As Goodwin (2002) points out, conflict and dispute are part of the social fabric of children's experiences, and play an important part in negotiating the social order. In this way, conflict is a critical activity for children as they construct, manage and shape their social worlds (Corsaro, 1997; Danby, 2005; Danby \& Baker, 2001; Maynard, 1985; Thorne, 1993). When children engage in moments of conflict, they are pursuing and testing their own social positions and, in so doing, they are shaping who they are as individuals, and in relationship with their co-twin.

In conflict, children pursue their own political agendas and test out their social positions, whether within peer or family contexts (Danby \& Baker, 2000; Maynard, 1985). In this way, their disputes, and the ways they manage them, could be described as fertile social opportunities for social learning, and its associated cognitive aspects. To date, however, there has been little understanding of twin children and how they account for their dealings with each other, specifically in matters of conflict. Yet, twins are compelled to share a social world from the start.

\section{The Study \\ Sample}

The sample was 30 twin pairs: 10 monozygotic (MZ; male), 10 dizygotic (DZ) same-sex (male/female), 10 DZ opposite-sex (male, female). They were volunteers recruited through the Australian Multiple Birth Association in a request for volunteers, disseminated through the local twin club newsletters and direct email. The children were aged between 5 and 10 years.

\section{Materials and Measures}

Data were collected using three methods:

- parent questionnaires

- pictorial representation of friendships

- audio-recorded conversations with children.

\section{Parent Questionnaires}

This provided demographic data and questioned the parents about the children's social experiences and relationship. Zygosity was determined using (1) questions concerning parent knowledge of zygosity and (2) a standard set of questions about physical similarity. The questionnaire also had a series of questions concerning the twin children's social experiences including time spent together (shared childcare and school classes, shared bedroom, shared visits to homes of friends), shared interests, shared friends and their co-twin relationship. Relationship questions asked about frequency of a range of interactions including arguing, fighting, playing, and ganging up on others. These were rated on a 4-point Likert scale, 0 (never) through 3 (always). From these relationship questions, three indices were derived:

1. Compatibility: Measured degree to which the twin pairs shared activities that suggested co-operation and agreement (playing at home, playing at school, sharing toys/games, ganging up together).

2. Conflict: Measured degree to which the twin pairs had disagreements within the interactions (teasing, physical fights, arguing).

3. Passivity: Measured degree to which the twin pairs shared activities that did not require agreement or disagreement (watching television, doing homework). 


\section{Twin 1}

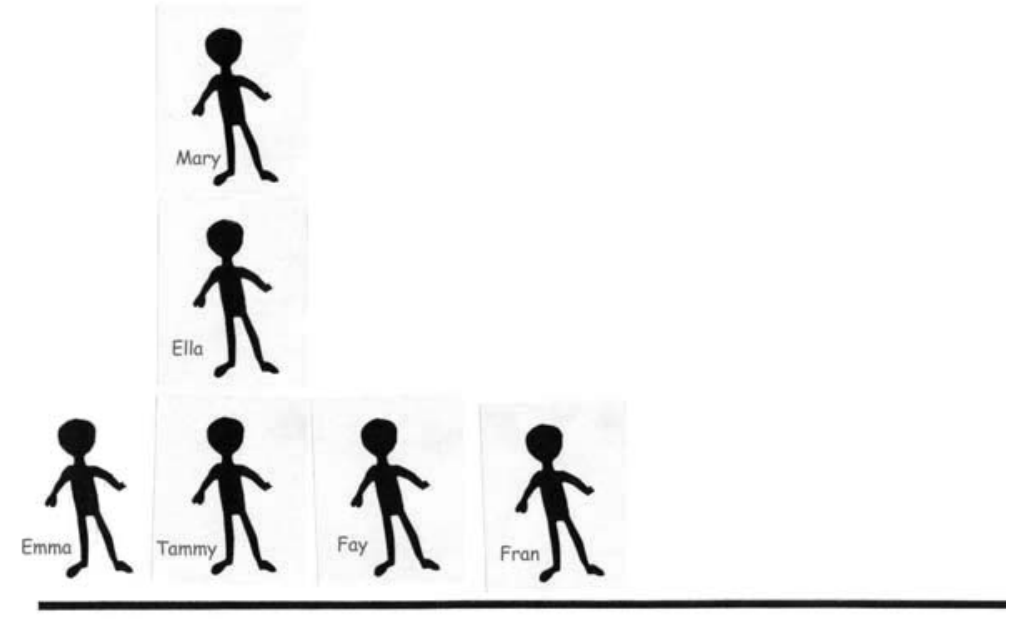

\section{Twin 2}

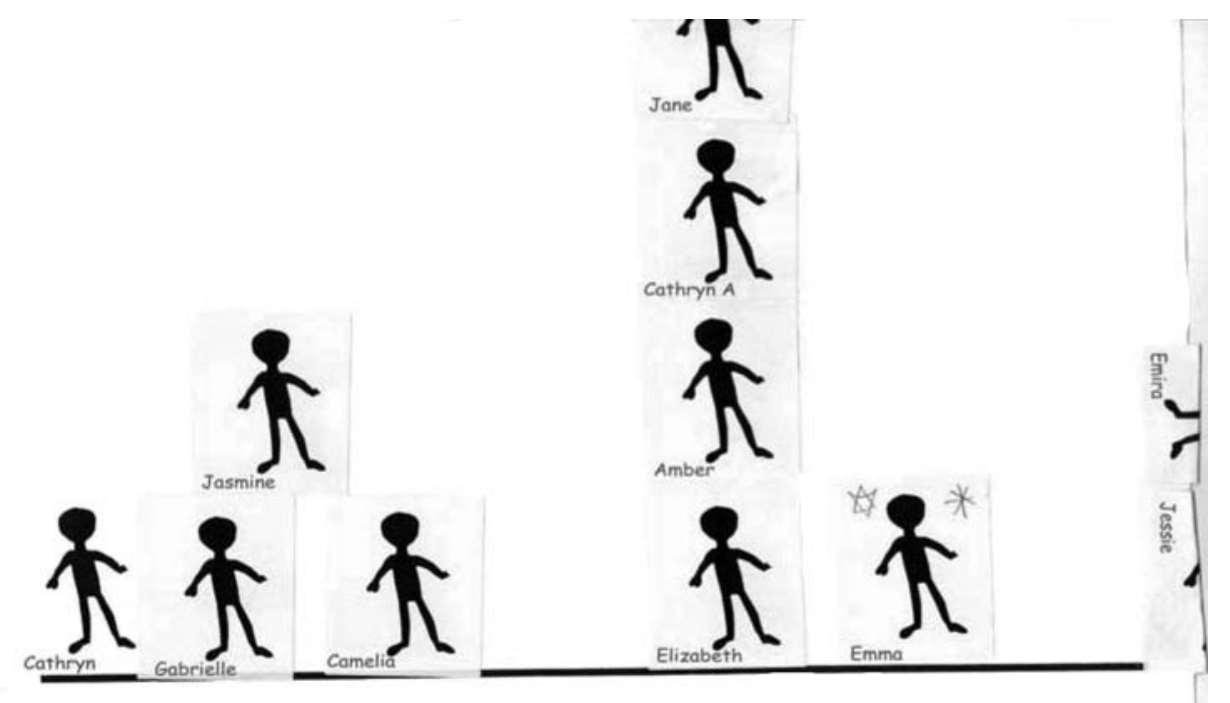

Figure 1

Example of a twin pair's pictorial representation of friendship and rank of co-twin.

Twin 1 did not include co-twin in the representation of friendship.

\section{Pictorial Representation of Friendships}

Children were invited to engage in the Friendship Sticker Task (Thorpe, 2003), a pictorial representation of friendship (see Figure 1).

The Friendship Sticker Task has been shown to be an effective and valid measure for obtaining data on young children's friendships (Thorpe, 2003). They were asked to represent their number and ranking (such as best friend) through the placement of stickers on a page. This became a concrete focus for interviewing the children about their friendships. To enable this identification of the number of friends they each had, and the closeness of their relationships with them, stickers were developed to represent the child, friends and co-twin. The stickers were stylized person figures so that they did not imply race or gender. Each child was represented by placing a sticker at the left of a horizontal line marked on paper.

Each child represented their friendships using stickers that were placed along a line next to a figure used to represent the target child. They were asked to choose stickers to represent their friends and place 
them in order of closeness to the sticker representing them. If they had friends equal in closeness, then the stickers were placed one above the other. The children wrote the names of each friend under the appropriate sticker. The child placed friends of greatest importance closer to the representation of themselves and those of less importance more distant. They were also asked to place their co-twin in the representation to indicate how they viewed them, relative to nonsibling friends.

Two separate measures were derived from the sticker representation task:

1. Shared friendships: This was a count of the number of individuals who were named and represented as friends by both twin children

2. Co-twin as friend: From the placement of the cotwin sticker in the sticker task, a rank was assigned to the co-twin ranging from 1 (extremely close) to 7 (not at all close).

The data on the sharing of friends and rank of co-twin form the background to understanding the social context of the twins who were interviewed.

\section{Audio-Recorded Conversations With Children}

The audio-recorded conversations with the children were used to analyze the documented twin and shared friend descriptions. Analyses examined commonalities and differences in their accounts of friendship and social relationships. The focus was on what the children introduced or made relevant through their descriptions of everyday social experiences of friendships. The conversation was used with the sticker representation task as the focus for talking about being a twin and social relationships, including exploration of the relationship with the co-twin. These audio-recorded conversations were later transcribed.

\section{$\overline{\text { Procedure }}$}

Data were collected during a single visit to each family home. A week prior to the visit, the parent questionnaire was sent to the parent along with a reminder and confirmation of the visit time. Parents were asked to complete the questionnaire prior to the visit. During the visit, the researcher worked, separately and privately, with each twin in the pair. The twin completed the pictorial representation of friendships and relationship with co-twin. The sticker representation task was used as the focus for the conversation, which included questioning (focused on the placement of co-twin sticker) about the relationship with their co-twin.

\section{Analysis of Numeric Data}

Analysis of numeric data asked whether twin type (MZ, DZ same-sex and DZ opposite-sex) differed in their history of sharing an environment, sharing friends and their relationship (compatibility, conflict, passivity). To this end, tests of difference for independent groups, Kruskal-Wallis or ANOVA (dependent on data distribution) were undertaken.

\section{Detailed Analysis of Transcribed Conversations of the DZSS Girls}

Based on the quantitative data, which indicated more variability in the DZ same-sex girls, the transcripts of the DZ same-sex girls were taken as the sample for detailed analysis. This group had higher mean conflict levels and this was of interest. In the analysis of transcript data, we focused on how the children themselves displayed their twinship and friendship identities, and how these identities were enacted in everyday experiences, such as conflict, at home and school. The analytic focus was on the participants' talk-in-interaction (Goodwin, 1990, 2000; Psathas, 1995) to investigate the conversations of the participants. Interviews are social interactions, and not a one-speaker phenomenon; thus, this article considers not just what the participants said, but how both researcher and participant co-constructed the interaction. This approach examines their talk in order to investigate their own reasoning methods for making sense of being a twin, particularly in a conflict situation.

Accounts of conflict and negotiation show the social membership categories of friendship and twinship to which the children orient and construct their social identities. An effective analytic tool used to investigate how members of particular groups recognize and describe themselves and others, is known as membership categorization analysis (Hester \& Eglin, 1997; Sacks, 1995). The focus is on the categorization work that each twin does as they go about making sense of their everyday and ongoing activities.

Everyday relationships are managed as ongoing and everyday practices. We investigate how co-twins proposed and took up particular courses of social action. By examining their everyday experiences from their own standpoints, we examined how children reasoned and accounted for their actions. In other words, the focus was on the ways the children assembled and negotiated their identities through their actions: 'identities in practice' (Antaki \& Widdicombe, 1998, p. 2). In this approach, identity is not a core and fixed attribute, but rather fluid and dynamic, built moment-by-moment through talk and social action, and in use (Danby \& Baker, 2000; Edwards, 1998). Twins have the particular social task of co-ordinating twinship and friendship activities, and identity work becomes the ongoing social resource with which to do this. This understanding of identity construction and social categorization differs from other approaches that draw on categorization analysis, such as self-categorization theory, in that this approach focuses on the locally constructed and situated use of categories (Edwards, 1998).

In everyday interactions, children have been described or categorized in a myriad of different ways, with descriptors such as competent, dependent, immature, adult-like, babyish, sensitive, assertive, feminine, and grown-up. In other words, membership categorization is defined as 'descriptors of types of persons' (Freebody, 2003, p. 159). These descriptions suppose a common-sense understanding. Identity is not 
predetermined but constructed by and through descriptions of one other. For example, a child who does not talk may be described using different descriptors. One observer may describe the child as 'shy and retiring'. Another might describe the same child as 'sullen and uncommunicative'. These differing descriptions are not only about the child under observation but also about those who are doing the actual describing. Descriptions can be brought to play into any social interactions, sometimes by us and sometimes by others.

In this article, we describe the twin relationship to include the categories that the twin children themselves used to describe each other, and their relationship with each other. For example, one child used the descriptors of herself as a 'lateral thinker' and she described her twin as, 'she thinks scientifically'. What becomes evident from these descriptors and accounts of activities, particularly when they are not mutually agreed upon, is children's social worlds under construction. For the children involved in this study, it seemed apparent that they had seriously considered, both individually and within the family, what it means to belong to the categories of twin and co-twin, and the associated activities involved in negotiating these relationships.

The approach taken here highlights the point that 'membership categorization is an activity carried out in particular local circumstances' (Hester \& Eglin, 1997, p. 22). Within the twin experience, the common-sense category that exists is the standard relational pair, such as identical twin-identical twin, boy twin-girl twin. However, 'it is in the use of these categories' (Hester \& Eglin, 1997, p. 20) that the social worlds are constituted. That is, it is only when these categories are invoked, or used, in the talk and action of the children that they were made relevant to other participants and observers. In other words, the focus is on whether children themselves (not the analyst) make these categories relevant as descriptors of themselves and others. This is the child standpoint at work.

Along with the category come particular activities or qualities known as category-bound activities or category-tied activities (Baker, 2000). The category boundedness is heard in the descriptor; for example, an identical twin might conventionally be expected to dress identically, particularly when they are babies, whereas adolescent identical twins might expect to be more independent in choosing their clothes to wear (see, e.g., Bacon, 2005).

In this article, we take up this concept of individuals applying category to ask:

- How do twins do 'being a twin'?

- What are the everyday practices of being a twin as they orient to everyday social interactions?

In showing how the twins in this study made sense of everyday activities and interactions, we can examine how they account for their orderly and accountable practices.

\section{Results and Discussion}

Shared Friendship

The median number of shared friendships were 3.5 for MZ twins, 3 for DZ same-sex twins and 2.5 for DZ opposite-sex twins. Kruskal Wallis analyses indicted that MZ twins share significantly more friends than either DZ same-sex $(p=.001)$ or DZ opposite-sex twins $(p=.000)$. There were no differences between same-sex and opposite-sex DZ twins.

\section{Ranking of the Co-Twin}

Median scores for rank of co-twin for each pair was for 2.5 for $\mathrm{MZ}$ pairs, 4 for $\mathrm{DZ}$ same-sex pairs and 2.5 for DZ opposite-sex pairs where 1 (extremely close) and 7 (not at all close), indicating that DZ same-sex pairs tended to view their co-twin less favorably than either of the other groups. However, Kruskal Wallis test of group difference did not indicate a significant difference $(p=.17)$.

\section{Compatibility and Conflict}

Analyses indicated significant differences between the groups on compatibility. Bonferroni post hoc tests indicated that the difference derives from MZ twins having higher scores (high score $=$ high compatibility) than either DZ same-sex or DZ opposite-sex pairs. There were no differences between DZ same-sex and DZ opposite-sex groups. Mean compatibility scores are presented in Figure 2.

No statistical differences were found for conflict scores by twin type, though mean scores for DZ samesex were raised compared with the other two groups (high score $=$ high conflict). The mean conflict scores are presented in Figure 3.

\section{Constructing Different Identities}

Freebody (2003) notes that statistical data can act as alert systems for researchers to then focus their attention on specific aspects of qualitative data. In this article, based on the results of quantitative analyses, the transcripts selected for analysis focuses on DZ same-sex girls. Evident across the data sets of the same-sex DZ

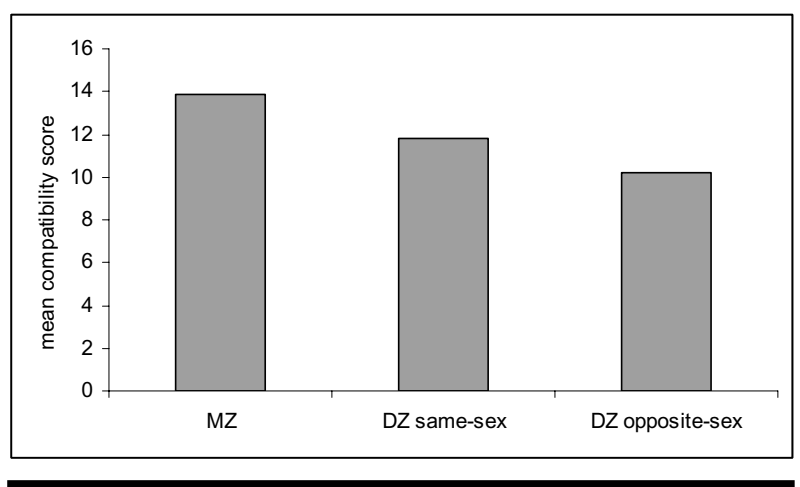

Figure 2

Mean compatibility scores by twin type (high score = high compatibility). 


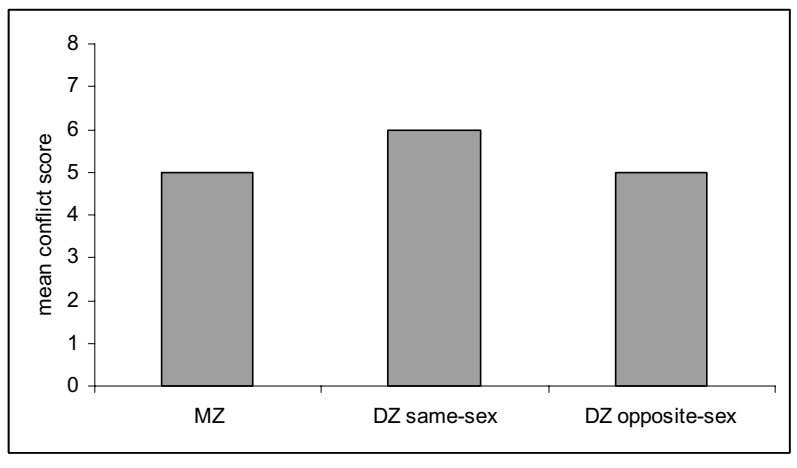

Figure 3

Mean conflict score by twin type (high score = high conflict).

co-twins was the girls' reporting that they were quite different from each other. They described how they thought about things differently, preferred different types of activities and chose different self-presentations in terms of clothing and hairstyles.

Examples noting the differences of thought, activity and self-presentation was most clearly identified by Mary and Laura in Extracts 1 and 2 below:

\section{Extract 1}

Researcher: Right, and so it sounds as if you think and do things quite differently.

Mary: Yep. Mum says we're like chalk and cheese.

Researcher: What do you think she means by that?

Mary: We're very different personalities like chalk is different to cheese.

Mary then went on to describe how she was different from her twin, Laura:

She's a bit messier.

I like to do different activities to her, we like different things.

A little later in the interview, Mary pointed out that she and Laura thought differently:

\section{Extract 2}

Mary: Yeah, I'm more of a lateral thinker or she thinks more scientifically type of thing.

Researcher: What do you mean by that, you're more of a lateral thinker?

Mary: I will usually think of things, what really happened, like we had a thing yesterday and you had to dress up as a wallaby using a tail except she just wanted to dress up normally as a wallaby with a jersey. I wore the wallaby stuff except I had ears and a tail.

Mary's categorization of herself as a 'lateral thinker' and her co-twin as a 'scientific thinker', and the accompanying explanation of an activity that aligns with these descriptors, show the identity work involved in constructing difference. Quite evident in this description is that the work of being a twin involves displays of thinking and acting quite differently. This account could be understood as moral work, in that each of Mary's descriptors of herself and Laura presents a particular type of person. In this instance, being either a lateral thinker or a scientific thinker denotes difference, but not necessarily a suggestion that one type of thinker is preferable over another.

The descriptors of difference are also evident in the school context. In the interview with Mary's co-twin, Laura, she points out that she and Mary think differently about preferences for particular school subjects:

\section{Extract 3}

Researcher: So how do you think you're different to Mary?

Laura: We're different in lots of ways. I think that we look different and we think differently, we're good at different subjects and stuff, we like different things.

However, Mary and Laura were not the only co-twins that describe themselves in this way. Anna and Brigid described similar sorts of differences. In the extracts below, Anna describes her co-twin as preferring different sorts of activities, and also preferring different hairstyles and styles of clothing:

\section{Extract 4}

Researcher: Do you do similar things to Brigid or different things do you think?

Anna: Umm different things?

Researcher: What sort of things do you do that are different?

Anna: Well she just sits and walks around and talking.

Researcher: And you like to be more active and she just likes to walk around?

Anna: Yeah.

$\cdots$

Researcher: What sorts of things do you think differently, it's a bit of a tricky question isn't it?

Anna: Well what clothes and some things I think are nice and she doesn't like them and our hair styles and sometimes things I do at school and she'll say that that's wrong and I have to do it this way.

Similarly, Brigid reports that she and her co-twin Anna also describe themselves as being different:

\section{Extract 5}

Researcher: And the things that you do that are different?

Brigid: I write different.

Researcher: You write different?

Brigid: She thinks my writing is off.

Evident here is the girls' treatment of their differences as fundamentally important in how they understood their relationship with their co-twin. This was obviously a matter of previous personal reflection, and also of family discussion (as indicated by Mary in Extract 1). The girls proposed different ways that they thought, 
acted and looked. Despite being part of the category of 'twins', it was important for them to establish their own individual features and, in so doing, construct an identity that was quite distinct from that of their co-twin. They made relevant, and oriented to, the idea that each was individual and separate in thought and action. In this way, they made themselves as 'being one kind of person rather than another' (Edwards, 1998, p. 32). The identity work that the girls made relevant here was not their similarity, but their difference.

There were moments, though, where the girls identified that they shared similar interests. Examples included doing homework together, listening to music, or competing with each other in swimming races in the family pool or in doing handstands. Engaging in homework side-by-side and listening to music can be described as quite passive activities, where the girls can participate in a shared time and place without actively engaging in shared ideas and actions. These following two examples show the girls' descriptions of these types of shared activity:

\section{Extract 6}

Laura: Sometimes we both do our homework at the same time.

Researcher: Do you help each other?

Laura: No not really.

\section{Extract 7}

Researcher: How about music? Do you like listening to music? Do you both like the same music?

Donna: Yeah, because we know when each other what they like because we both like the same music.

Here, Laura and Donna make visible how they orient to a particular shared social world. The shared passive activities show neither girl jostling for a social position of power in these moments. In these situations, where neither twin is in direct competition, a different 'alliance of interest' (Maynard, 1985, p. 210) emerges within the relationship. The girls' descriptions of 'being a twin' is one where they can participate in shared, albeit passive, activities. On the other hand, competitive sports activities suggest another social agenda at work, one where the existing social order of the twin relationship is under challenge, and so a redirection of social organisation is possibly always under construction.

\section{Conflict, Competition and Challenge}

Competition and challenge, sometimes leading to verbal and physical conflict, suggests that the everyday relationship of the twin with her co-twin is always being negotiated and realigned. As a consequence, tensions exist. The physical contestation and competition across sports and activities, work to build particular types of social order that appear neither safe nor secure for either co-twin. The girls' accounts show how they work to construct and realign their positions of power, identity and place within the twin relation- ship. Here, it seems that the twin relationship is one where there is not a 'sense of security' for either participant but, rather, a relationship where identity and social relationship constructions are always underway.

The girls in this study reported conflict over matters such as shared friends and playing games. In this study, the same-sex DZ girls identified fewer shared friends than same-sex MZ girls. Laura sums this up in the following way:

\section{Extract 8}

Researcher: Is there anything else you would like to tell me about being a twin?

Laura: Sometimes it gets really annoying being a twin because you're always trying to be better than the twin. And, it's like, sometimes you just want to be by yourself and that hard because ... yeah ...

Researcher: So you're always wanting to be better, you say, than your twin.

Laura: Yeah.

Laura here alludes to how she feels that she must compete with her co-twin. Her account can be heard as one of contestation. She refers to two conditions: 'sometimes you just want to be by yourself' and 'you're always wanting to be better'. As Laura suggests later, having the attribute of being the same age contributes to this sense of having to compete: 'I think it's because she's the same age and about the same level so we try and be better.'

Another aspect of the co-twin's social worlds is the matter of friendships. The same-sex DZ girls reported few shared friends. As Laura suggests below, this is another social arena where there is competition between the co-twins:

\section{Extract 9}

Researcher: So do you share any friends with Mary?

Laura: Not really.

Researcher: Has it always been like that? Or when you were little?

Laura: When I was little, I had a really good friend called Jane and I was a bit annoyed because Mary started being her friend and then she stopped being my friend and stuff.

In this example, and in the extracts below, each twin reports her co-twin's behavior as an infraction of some kind. For example, Rachel reports that Donna cheats when playing Monopoly, and Brigid points out that Donna hit her on the head 'for no good reason':

\section{Extract 10}

Rachel: Well sometimes we play Monopoly on the table here and sometimes we go out and ride our bikes but most of the time we usually fight.

Researcher: Really.

Rachel: Yeah.

Researcher: What sort of things do you do in a fight? 
Rachel: Pull hair.

Researcher: Ooh. What do you fight over? What makes you have a fight?

Rachel: Coz sometimes when we're playing a game, sometimes Donna cheats and I get really really angry and then she starts a fight and just go like that coz I think, coz it's between me and her I should [unheard] and say that you're a cheater.

\section{Extract 11}

Brigid: Yes and she got cranky at me.

Researcher: Did you also get cranky?

Brigid: A little bit.

Researcher: Do you get cranky at each other very much?

Brigid: Yes.

Researcher: Would you say a lot, sometimes?

Brigid: Sometimes.

Researcher: What sort of things makes you cranky?

Brigid: She hits me on the head for no good reason.

In any account, it is not enough to let the pairing, such as DZ same-sex twin, stand alone. Rather, the twin providing the account presents to the hearer (in this case, the researcher) details of more specific identity (Hester, 2000). In the accounts above, it is not enough to hear about the category of twin, but invoked instead is the category of twin who has breached some norm of social order, such as stealing a friend, cheating at Monopoly, or engaging in physical violence. So while it is possible for twin-twin to be a relevant pair in some circumstances, for the purposes of providing an account, a more likely account provides some qualification. The category selections of 'cheating twin', 'violent twin' and 'injured party' here allocate blame to put the teller in the best frame possible. Thus, in addition to the attribute of 'difference', breaches of social order may be invoked as reasons for not getting on with the co-twin.

The accounts by the children about their co-twin is understood as their 'sense-making work through which participants engage in explaining, attributing, justifying, describing and otherwise finding possible sense of orderliness in the various events, people, places, and courses of action they talk about' (Baker, 2002, p. 781). In this instance, the children, in orienting to the researcher category assigned to them, that of twin, accounted for themselves as competent members of the social category of 'being a twin'. The children's work, then, was more than reporting or responding to the interviewer's questions, but rather presenting particular versions of how things are or could be (Baker, 2002). In this way, the researcher (and reader) generates versions of social life in order to gain access to, and understanding of, the social world of being a twin. The accounts are treated as neither fact nor story, but rather as social versions of twinship reproduced for the researcher. This does not reduce the veracity or significance of the transcribed interviews, but rather serves to show how the work of the interview is itself also a social construction.

\section{$\overline{\text { Conclusion }}$}

The process of researchers listening to children regarding events and experiences that relate to them requires respecting children from their own standpoints (Mayall, 2002). In these accounts, the researcher viewed the children as competent informants of their own experiences. In this way, the children's accounts were purposefully designed for the recipient, the researcher. In offering the children this social interactional space, a different type of social order was established where children were assumed to be active in constructing their social worlds.

Examining the standpoints of the children shows how they reasoned and accounted for their relationships with their co-twins. In each account, each girl assembled and negotiated particular sorts of identity for herself. Each brought certain attributes to light as they described themselves and their co-twins. In these accounts, the girls each described who they were from a range of possible categorizations. They oriented to a number of categories, including the 'lateral thinker' and the twin who was an 'injured party'. Conflict was one way of testing particular social alignments and positions of power, and in this process, constructing particular sorts of identities for themselves. In this way, identity became a resource that each girl drew upon to describe the social actions of the other. By identifying their attributes of difference through descriptors of the types of activities and preferences, they presented themselves as having different individual social attributes and different identities. Being a DZ same-sex girl twin involved more than doing or thinking things differently. It involved generating, at times, a version of the co-twin that breached some norm of social order. Evident here is the complexity of social interactions in which the twins engage everyday with each other.

This article focused on being a DZ same-sex girl twin. The selection of this sample was justified by quantitative analyses of parent reports that suggested higher levels of conflict in this group. This focus allowed us to look in detail at the children's descriptions of their interactions with each other. This analysis raises two matters for further consideration. First, the ability to assess group differences in frequency and intensity of conflict and compatibility by twin type would require larger sample sizes than those analyzed here. Second, the accounts of the twin children raise three questions for future research:

1. Are these interactions specific to twin relationships?

2. Are these interactions specific to girls?

3. Are these interactions specific to being a DZ twin? 


\section{References}

Antaki, C., \& Widdicombe, S. (1998). Identity as an achievement and as a tool. In C. Antaki \& S. Widdicombe (Eds.), Identities in talk (pp. 1-14). London: Sage.

Bacon, K. (2006). 'It's good to be different': Parent and child negotiations of 'twin' identity. Twin Research and Human Genetics, 9, 141-147.

Baker, C. D. (2000). Locating culture in action: Membership categorisation in texts and talk. In A. Lee \& C. Poynton (Eds.), Culture and text: Discourse and methodology in social research and cultural studies (pp. 99-113). St Leonards, Australia: Allen \& Unwin.

Baker, C. D. (2002). Ethnomethodological analyses of interviews. In J. Gubrium \& J. Holstein (Eds.), Handbook of interview research: Context and method (pp. 777-795). Thousand Oaks, CA: Sage.

Christensen, P., \& James, A. (2000). Childhood diversity and commonality: Some methodological insights. In P. Christensen \& A. James (Eds.), Research with children: Perspectives and practices (pp. 160-178). London: Falmer Press.

Corsaro, W. A. (1997). The sociology of childhood. Thousand Oaks, CA: Pine Forge Press.

Corsaro, W. A., \& Molinari, L. (1990). From seggiolini to discussione: The generation and extension of peer culture among Italian preschool children. International Journal of Qualitative Studies in Education, 3, 213-230.

Danby, S. (2005). Preschool girls, conflict and repair. In J. Mason \& T. Fattore (Eds.), Children taken seriously: In theory, policy and practice (pp. 172-181). London: Jessica Kingsley.

Danby, S., \& Baker, C. D. (2000). Unravelling the fabric of social order in block area. In S. Hester \& D. Francis (Eds.), Local educational order: Ethnomethodological studies of knowledge in action (pp. 91-140). Amsterdam, the Netherlands: John Benjamins.

Danby, S., \& Baker, C. D. (2001). Escalating terror: Communicative strategies in a preschool classroom dispute. Early Education and Development, 12, 343-358.

Danby, S., \& Farrell, A. (2004). Accounting for young children's competence in educational research: New perspectives on research ethics. Australian Educational Researcher, 31, 35-49.

Danby, S., \& Farrell, A. (2005). Exploring consent and participation. In A. Farrell (Ed.), Exploring ethical research with children (pp. 49-67). Milton Keynes, UK: Open University Press.

Danby, S., \& Thorpe, K. (2004, July). Negotiating conflict in a twin relationship. Paper presented at the 11 th International Congress on Twin Studies, Denmark.

Edwards, D. (1998). The relevant thing about her: Social identity categories in use. In C. Antaki \& S. Widdicombe (Eds.), Identities in talk (pp. 15-33). London: Sage.
Edwards, R., \& Alldred, P. (1999). Children and young people's views of social research: The case of research on home-school relations. Childhood, 6, 261-281.

Freebody, P. (2003). Qualitative research in education: Interaction and practice. London: Sage.

Goodwin, C. (2000). Action and embodiment within situated human interaction. Journal of Pragmatics, 32, 1489-1522.

Goodwin, M. H. (1990). He-said-she-said: Talk as social organization among black children. Bloomington, IN: Indiana University Press.

Goodwin, M. (2002). Exclusion in girls' peer groups: Ethnographic analysis of language practices on the playground. Human Development, 45, 392-415.

Hallett, C., \& Prout, A. (Eds.). (2003). Hearing the voices of children: Social policy for a new century. London: RoutledgeFalmer.

Hester, S. (2000). The local order of deviance in school: Membership categorisation, motives and morality in referral talk. In S. Hester \& D. Francis (Eds.), Local educational order: Ethnomethodological studies of knowledge in action (pp. 197-222). Amsterdam, the Netherlands: John Benjamins.

Hester, S., \& Eglin, P. (1997). Membership categorization: An introduction. In S. Hester \& P. Eglin (Eds.), Culture in action: Studies of membership categorization (pp. 1-23). Washington, DC: International Institute for Ethnomethodology and Conversation Analysis \& University Press of America.

James, A., Jenks, C., \& Prout, A. (1998). Theorising childhood. Cambridge, UK: Polity Press.

Mason, J., \& Fattore, T. (Eds.). (2005). Children taken seriously: In theory, policy and practice. London: Jessica Kingsley.

Mayall, B. (2002). Towards a sociology for childhood: Thinking from children's lives. Buckingham, UK: Open University Press.

Maynard, D. W. (1985). On the functions of social conflict among children. American Sociological Review, 50, 207-223.

Plomin, R. (1993). Genetics and experience: The interplay between nature and nurture. Thousand Oaks, CA: Sage.

Psathas, G. (1995) Conversation analysis: The study of talk-in-interaction (Vol. 35). Thousand Oaks, CA: Sage.

Prout, A., \& Hallett, C. (2003). Introduction. In C. Hallett \& A. Prout (Eds.), Hearing the voices of children: Social policy for a new century (pp. 1-8). London: RoutledgeFalmer.

Sacks, H. (1995). Lectures on conversation (G. Jefferson, Trans.; Vols. I and II). Oxford, UK: Blackwell. 
Scarr, S. (1992). Developmental theories for the 1990s: Development and individual difference. Child Development, 63, 1-19.

Stewart, E. A. (2003). Exploring twins: Towards a social analysis of twinship. Houndmills, UK: Palgrave Macmillan.

Tayler, C., Farrell, A., Tennent, L., \& Patterson, C. (2004). Child and family hubs and social capital. Commission for Children and Young People Issue Paper, 3, 1-7.
Thorne, B. (1993). Gender play: Girls and boys in school. New Brunswick, NJ: Rutgers University Press.

Thorpe, K. J. (2003). Twins and friendship. Paper presented at Multiple Pregnancy Conference, Melbourne, Australia.

Waksler, F. (1991). Studying children: Phenomenological insights. In F. Waksler (Ed.), Studying the social worlds of children: Sociological readings (pp. 60-69). London: Falmer Press. 